\title{
Relationship Between Total Rewards Perceptions and Work Engagement Among Chinese Kindergarten Teachers: Organizational Identification as a Mediator
}

\author{
Dongying $\mathrm{Ji}^{1}$ and $\mathrm{Li} \mathrm{Cui}{ }^{2 *}$ \\ ${ }^{1}$ Faculty of Education, Beijing Normal University, Beijing, China, ${ }^{2}$ College of Education, Huaibei Normal University, Huaibei, \\ China
}

Kindergarten teachers' engagement in work is influenced by many factors. Total rewards perceptions, as an individual's evaluation of the rewards provided by the organization, may promote work engagement when it can meet their intrinsic and extrinsic work demands. To explore the relationship between kindergarten teachers' total rewards perceptions and work engagement, and the mediating role

OPEN ACCESS

Edited by:

Joana Vieira Dos Santos,

University of Algarve, Portugal

Reviewed by:

Lorenzo Avanzi,

University of Trento, Italy

Wong Yau Ho Paul,

Tung Wah College, Hong Kong

*Correspondence:

Li Cui

cuili1602@163.com

Specialty section:

This article was submitted to

Health Psychology,

a section of the journal

Frontiers in Psychology

Received: 01 January 2021 Accepted: 16 March 2021

Published: 29 April 2021

Citation:

Ji D and Cui L (2021) Relationship Between Total Rewards Perceptions and Work Engagement Among Chinese Kindergarten Teachers:

Organizational Identification as a Mediator. Front. Psychol. 12:648729.

doi: 10.3389/fpsyg.2021.648729 of organizational identification, a survey was conducted among 1,014 kindergarten teachers applying the Chinese versions of the Total Rewards Perceptions Scale for Kindergarten Teacher, Kindergarten Teacher Organizational Identification Scale, and Kindergarten Teacher Work Engagement Scale. The results showed that kindergarten teachers' total rewards perceptions and its four factors were positively correlated with organizational identification and work engagement. Organizational identification was positively related to work engagement. Organizational identification partially mediated the relationship between total rewards perception and work engagement among kindergarten teachers. We discussed the result of the relationship between total rewards perceptions, organizational identification, and work engagement among Chinese kindergarten teachers.

Keywords: total rewards perceptions, kindergarten teachers, organizational identification, work engagement, mediating effect

\section{INTRODUCTION}

In the past decades, there has been a growing interest in work engagement as research found that engagement is related to meaningful outcomes (Soares and Mosquera, 2019). Work engagement represents a positive, fulfilling, work-related state of mind that is characterized by vigor (high levels of energy and mental resilience), dedication (work involvement, enthusiasm, and inspiration), and absorption (work concentration and immersion) (Schaufeli et al., 2002). Previous studies have shown that levels of teachers' work engagement have a strong influence over job performance, intention to quit teaching, and academic achievement of their students (Roth et al., 2007; Bakker et al., 2008; Duckworth et al., 2009). The teachers' behavior, belief, and emotional dimension are related to the results obtained by the students (Perera et al., 2018). Kindergarten teachers care for 
and teach children between the ages of three and six. This requires them to devote more energy to cultivating and supporting children's social, emotional, and academic development (Coplan et al., 2015; Stasio et al., 2020).

Total rewards are considered as the critical way that affects members' motivation to join and stay with the organization, and support organizational effectiveness and members' wellbeing (Muse et al., 2008; Chiboiwa et al., 2010; Newman and Sheikh, 2012a). Total rewards systems have a greater influence on individuals than the single reward because the total rewards system is more flexible to meet the intrinsic and extrinsic demands of organizational members (Armstrong and Stephens, 2005). Monetary rewards and nonmonetary rewards are included in total rewards. Among them, monetary rewards include pay perception, benefits perceptions, etc.; non-monetary rewards include learning and development opportunities, feedback and appreciation for work, etc. (Heneman and Tansky, 2002). Strom et al. (2014) found that engagement levels of organizational members depend on their perceptions of the rewards. Social Exchange Theory also indicates that positive work behaviors and attitude of employees are always directed by work resources (Blau, 1964). From this perspective, when individuals perceive resources from their organization, they feel positive about the organization and its values and are willing to engage in work toward the achievement of the organization's goals ( $\mathrm{Li}$ and $\mathrm{Wu}$, 2014). A rewarding work environment contributes to employees becoming more engaged in their work (Roberts and Davenport, 2002).

The Conservation of Resource Theory proposed by Hobfoll (1989) has believed that individuals always have the tendency to acquire, occupy, and maintain important resources. Sufficient work resources can enhance employees' work motivation, increase work engagement, and improve work performance (Demerouti and Bakker, 2011; Bakker et al., 2014). Rewards, as a kind of resource that employees can access, significantly affect their work engagement (Gulyani and Sharma, 2018). Previous studies have compared the impact of non-monetary rewards and monetary rewards on work engagement and found that the effect of monetary rewards on work engagement is lower than that of non-monetary rewards (Scott and McMullen, 2010). Rewards represent what the organization can offer its employees (Morgan et al., 2013; Chinyio et al., 2018). Therefore, teachers may be more willing to devote themselves to the work if they perceive a greater amount of benefits (e.g., monetary rewards, non-monetary rewards) offered by the kindergarten.

Organizational identification, as the shared beliefs of members (Stuart and Whetten, 1985), represents employees' sense of belonging to the organization (Ashforth et al., 2008) and delimits a set of cognitive, emotional, and behavioral aspects that are consistent with an identity as a member of the organization (Haslam and Ellemers, 2006). It refers to a connection with the organization, and the expectation to improve the status of organization members (Hogg and Terry, 2000). Organizational identification is significantly affected by total rewards perceptions (Yang and Yang, 2015). Du (2013) indicated that working conditions, rewards, and benefits also have a significant impact on organizational identification. Low organizational identification may be due to the imbalance between effort and rewards in the work environment (Guglielmi et al., 2017). The perception of low rewards from the organization may instill a negative social exchange process so that employees are not encouraged to care about the organization (Cropanzano et al., 2003). From the perspective of social exchange theory, some researchers indicated that individuals' identification with organizations partly stems from individuals' perception of organizational support, and it represents the social exchange between individuals and organizations (Shen, 2007). Some studies have shown that a high level of organizational support perception will prompt individuals to show a higher level of organizational identification (Shen et al., 2014; Edwards and Peccei, 2015; Lam et al., 2016). Organizational identification is an important antecedent of work engagement and has a significant impact on work engagement (Riketta, 2005; Guo and Zhang, 2016). Van Dick et al. (2004) explained that organizational identification can improve employees' job satisfaction, and higher job satisfaction may also increase employees' emotional and cognitive involvement in work. Organizational identification not only is influenced by the perception of total rewards but also significantly influences work engagement.

Little research examined organizational identification of kindergarten teachers and the mechanism through which work resources (total rewards components) affect kindergarten teacher work attitude (i.e., teacher work engagement). This study expects to expand the research on organizational identification and explore the mediating effect of organizational identification with Chinese kindergarten teachers as the object. Thus, the current study aims to examine the relationship between total rewards perceptions and work engagement among kindergarten teachers, surveying the mediating effect of organizational identification in the relationship between total rewards perceptions and work engagement among Chinese kindergarten teachers. Accordingly, the main hypothesis of this study is as follows:

Hypothesis 1: Correlations between total rewards perceptions, organizational identification, and work engagement among kindergarten teachers are positive and significant.

Hypothesis 2: Organizational identification mediates the relations between total rewards perceptions and work engagement among kindergarten teachers.

The proposed integrated model is presented in Figure 1.

\section{METHODS}

\section{Participants}

All participants were kindergarten professional teachers, excluding the nurses. In this study, a convenient sampling method was adopted to manage the survey and collect large sample data (Axinn and Pearce, 2006). After obtaining consent from the kindergarten principal, the investigators enter the kindergarten to distribute and return questionnaires in 2019. 


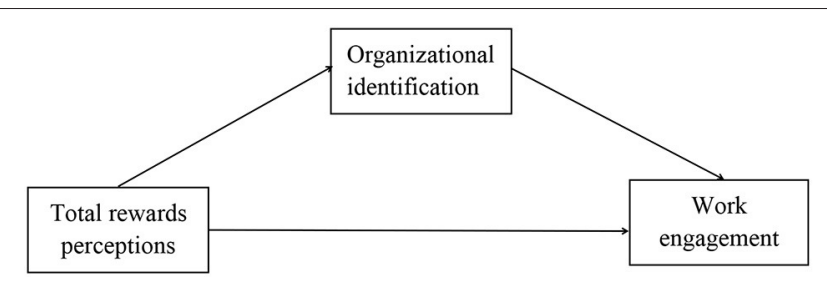

FIGURE 1 | Hypothesized model.

TABLE 1 | Demographic information of kindergarten teacher sample $(n=1,014)$.

\begin{tabular}{lr}
\hline Characteristics & $n(\%)$ \\
Area & \\
Urban & $690(68.0)$ \\
Rural & $324(32.0)$ \\
Education level & \\
$\leq$ High school & $96(9.5)$ \\
Vocational school & $429(42.3)$ \\
$\geq$ University degree & $489(48.2)$ \\
Teaching experience & \\
$\leq 5$ years & $614(60.6)$ \\
$6-10$ years & $220(21.7)$ \\
$11-15$ years & $84(8.3)$ \\
$16-20$ years & $39(3.8)$ \\
$\geq 21$ years & $57(5.6)$ \\
\hline
\end{tabular}

The teachers who participated in this survey were promised that their information and responses would be confidential and anonymous. A total of 1,100 questionnaires were distributed to kindergarten teachers in Henan, Anhui, and Xinjiang, China; 1,030 questionnaires were actually returned, with a response rate of $93.6 \%$. Of these 1,030 questionnaires, 1,014 were valid, with an effectivity rate of $92.2 \%$. These 1,014 valid questionnaires formed the final sample of this study. The demographic characteristics of the samples are shown in Table 1.

\section{Measures}

\section{Total Rewards Perceptions for Kindergarten Teacher}

The Total Rewards Perceptions Scale for Kindergarten Teachers was adapted from the four-factor total rewards perceptions scale that was designed by Chinese researcher Yang and Yang (2015), which was validated on the basis of a total rewards model that includes compensation, benefits, work-life balance, performance and recognition, and development and career opportunities proposed by the WorldatWork (2007). The scale, consisting of 21 items, was used to measure four dimensions of total rewards perceptions: work-life balance perceptions (WLBP; e.g., kindergarten guarantees teachers' rest time), development and career opportunity perceptions (DCOP; e.g., kindergarten provides teachers with a clear path to future advancement), working conditions perceptions (WCP; e.g., kindergarten pays five social insurance and one housing fund for teachers in full and on time), and wage level perceptions (WLP; e.g., the wage level of the kindergarten matches with my professional skills).
The 21 items were measured using a five-point Likert-type scale, ranging from 1 (very poor) to 5 (very well). The higher the score on the four dimensions, the better the total rewards perceived by kindergarten teachers. In this study, Cronbach's $\alpha$ was 0.96 . Internal consistency was 0.89 for WLBP, 0.92 for DCOP, 0.85 for WCP, and 0.92 for WLP.

\section{Kindergarten Teacher Work Engagement}

Kindergarten Teacher Work Engagement was measured using the Utrecht work engagement scale (UWES) developed by Schaufeli et al. (2002). The scale has been used in different samples of Chinese and shows good reliability and validity (Wang et al., 2015; Li and Wu, 2016). This scale included three dimensions: vigor (e.g., I can continue working for very long periods at a time), dedication (e.g., I am proud of the work that I do), and absorption (e.g., I get carried away when I am working). The responses for all of the items were obtained on a five-point Likert scale ( $1=$ strongly disapprove, $5=$ strongly approve). In this study, Cronbach's $\alpha$ was 0.96 . Internal consistency was 0.89 for vigor, 0.92 for dedication, and 0.90 for absorption.

\section{Kindergarten Teacher Organizational Identification}

Kindergarten Teacher Organizational Identification Scale was adopted from the Organizational Identification Scale developed by Mael and Ashforth (Mael and Ashforth, 1992). This scale has illustrated good reliability and validity in Chinese samples (Wang et al., 2016; Song et al., 2019). The scale consisted of six items, which were scored on a five-point Likert scale from 1 (strongly disagree) to 5 (strongly agree). A sample item was "I think that the success of my kindergarten is also my success." In this study, Cronbach's $\alpha$ was 0.86 .

\section{Control Variables}

We controlled the potential effect of demographic variables (area, education level, and teaching experience) on dependent and mediating variables, as all of them may impact employee work engagement.

\section{Procedure}

This project was reviewed and approved by the Ethics Committee of Huaibei Normal University and complied with the Declaration of Helsinki involving human subjects. We obtain consent from the kindergarten principal to enter the kindergarten to distribute questionnaires in 2019. Before the test, participants would be given informed consent and were informed about the research content and their rights. We also informed participants that completion of the test was entirely voluntary and that they had the right to decline to complete the test. The test would continue after participants confirm informed consent. If participants refused to participate, the test ended.

\section{Data Analysis}

In the current study, we used SPSS 22 software to analyze the relationship between total rewards perceptions, organizational identification, and work engagement among kindergarten teachers. The descriptive statistics (mean and standard deviation) were calculated to measure the level of all variables. Bivariate 
TABLE 2 | Descriptive statistics and correlations among variables.

\begin{tabular}{|c|c|c|c|c|c|c|c|c|c|c|}
\hline Variable & 1 & 2 & 3 & 4 & 5 & 6 & 7 & 8 & 9 & 10 \\
\hline 1. Area & - & & & & & & & & & \\
\hline 2. EL & $0.12^{\star \star}$ & - & & & & & & & & \\
\hline 3. TE & $-0.94^{\star \star}$ & $0.19^{\star \star}$ & - & & & & & & & \\
\hline 4. TRP & 0.038 & 0.053 & $-0.08^{\star}$ & - & & & & & & \\
\hline 5. WLBP & -0.03 & $-0.14^{\star \star}$ & $0.07^{*}$ & $0.87^{\star \star}$ & - & & & & & \\
\hline 6. DCOP & -0.02 & $-0.14^{\star \star}$ & 0.04 & $0.92^{\star \star}$ & $0.79^{\star \star}$ & - & & & & \\
\hline 7. WCP & $0.14^{\star \star}$ & $0.07^{\star}$ & $0.07^{\star}$ & $0.83^{\star \star}$ & $0.56^{\star \star}$ & $0.66^{\star \star}$ & - & & & \\
\hline 8. WLP & 0.04 & $-0.08^{\star \star}$ & -0.00 & $0.91^{\star \star}$ & $0.70^{\star \star}$ & $0.80^{\star \star}$ & $0.72^{\star \star}$ & - & & \\
\hline 9. Ol & 0.03 & $0.10^{\star \star}$ & $0.14^{\star \star}$ & $0.30^{\star \star}$ & $0.22^{\star \star}$ & $0.26^{\star *}$ & $0.28^{\star \star}$ & $0.28^{\star *}$ & - & \\
\hline 10. WE & -0.03 & $-0.08^{\star \star}$ & $0.17^{\star \star}$ & $0.62^{* \star}$ & $0.59^{* *}$ & $0.61^{\star \star}$ & $0.40^{\star *}$ & $0.58^{\star *}$ & $0.41^{\star \star}$ & - \\
\hline M & - & - & 1.72 & 3.81 & 3.75 & 3.79 & 3.92 & 3.78 & 4.14 & 3.94 \\
\hline SD & - & - & 1.13 & 0.73 & 0.86 & 0.79 & 0.84 & 0.82 & 0.72 & 0.73 \\
\hline
\end{tabular}

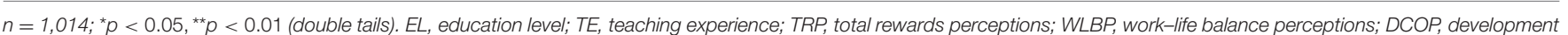
and career opportunity perceptions; WCP, working conditions perceptions; WLP, wage level perceptions; Ol, organizational identification; WE, work engagement.

correlations were used to examine correlations between socioanagraphical variables, kindergarten teachers' total rewards perceptions (including WLBP, DCOP, WCP, and WLP), organizational identification, and work engagement. We used structural equation modeling (SEM) in Mplus 8.0 to investigate the impact of organizational identification on the relationship between total rewards perceptions and work engagement. The comparative fit index (CFI), the Tucker-Lewis index (TLI), the root mean square error approximation (RMSEA), and the standardized root mean square residual (SRMR) were used to estimate the model fit information. Hu and Bentler (1999) suggested that TLI, CFI $>0.90$, and RMSEA, SRMR $<0.08$ showed the model fitted well. The bootstrapping method of bias correction was used to verify the significance of the mediation effect. No zero between the lower level and higher levels of the confidence interval means that a mediating effect is significant (Hayes, 2009).

\section{RESULTS}

\section{Descriptive Statistics and Correlations Among the Variables}

Table 2 presents the descriptive statistics and correlations among variables. Among the four factors of total rewards perceptions, WCP $(\mathrm{M}=3.92, \mathrm{SD}=0.84)$ scored higher than WLBP $(\mathrm{M}=3.75, \mathrm{SD}=0.86)$, $\mathrm{DCOP}(\mathrm{M}=3.79, \mathrm{SD}=0.79)$, and $\mathrm{WLP}(\mathrm{M}=3.78, \mathrm{SD}=0.82)$. The mean score of organizational identification and work engagement were $4.14(\mathrm{SD}=0.72)$ and $3.94(\mathrm{SD}=0.73)$. Kindergarten teachers' total rewards perceptions were positively associated with work engagement $(r=0.62, p<0.01)$ and organizational identification $(r=0.30$, $p<0.01)$. Four factors of total rewards perceptions were positively related to work engagement (WLBP, $r=0.59, p<0.01$; DCOP, $r=0.61, p<0.01$; WCP, $r=0.40, p<0.01$; WLP, $r=0.58, p<0.01$ ) and organizational identification (WLBP, $r=0.22, p<0.01$; DCOP, $r=0.26, p<0.01$; WCP, $r=0.28$, $p<0.01$; WLP, $r=0.28, p<0.01$ ). The correlation among DCOP and work engagement was higher than that among the other three factors of total rewards perceptions and work engagement. Organizational identification correlated positively with work engagement $(r=0.41, p<0.01)$. H1 was supported. In addition, education level and teaching experience are correlated with TRP, $\mathrm{OI}$, and WE to different degrees. Therefore, education level and teaching experience were controlled in subsequent analysis.

\section{Mediating Effect}

A standardized structural equation model was adopted to investigate the mediation effect of organizational identification in the relationship between total rewards perceptions and work engagement. We control the demographic variables (education level and teaching experience) in the structural equation model. The model consisted of total rewards perceptions, organizational identification, and work engagement. The results showed this model had good fitting indices: $\chi^{2}=184.47$ $(p<0.001), \mathrm{df}=67, \chi^{2} / \mathrm{df}=2.75$, CFI $=0.96$, TLI $=0.95$, RMSEA $=0.06[90 \%$ CI $=(0.05,0.07)]$, SRMR $=0.04$. Total rewards perceptions positively predicted organizational identification $(\beta=0.40, p<0.001)$. Organizational identification $(\beta=0.34, p<0.001)$ significantly positively predicted work engagement. The direct effect of total rewards perceptions on work engagement was significant $(\beta=0.51, p<0.001)$. Hence, the results of the indirect effects demonstrated that organizational identification $(\beta=0.14, p<0.001)$ mediated the correlation between total rewards perceptions and work engagement. Furthermore, bootstrapping test showed that the mediation effect of organizational identification was significant $[95 \% \mathrm{CI}=(0.121,0.230)]$ (see Table 3 and Figure 2). Thus, H2 was supported.

\section{DISCUSSION}

The present study examined the correlation among total rewards perceptions, organizational identification, and work engagement among Chinese kindergarten teachers. Past studies 
TABLE 3 | Mediating effect of organizational identification.

\begin{tabular}{lcccc}
\hline & $\boldsymbol{\beta}$ & $\boldsymbol{p}$ & LLCI & ULCI \\
\hline $\mathrm{TRP} \rightarrow$ WE (c) & 0.51 & $<0.001$ & 0.436 & 0.570 \\
$\mathrm{TRP} \rightarrow$ OI (a) & 0.40 & $<0.001$ & 0.332 & 0.472 \\
$\mathrm{OI} \rightarrow \mathrm{WE}(\mathrm{b})$ & 0.34 & $<0.001$ & 0.269 & 0.422 \\
$\mathrm{TRP} \rightarrow$ OI $\rightarrow$ WE & 0.14 & $<0.001$ & 0.098 & 0.180
\end{tabular}

$c$, the direct effect of total rewards perceptions on work engagement; a, the effect of total rewards perceptions on organizational identification; $b$, the effect of organizational identification on work engagement; TRP, total rewards perceptions; OI, organizational identification; WE, work engagement.

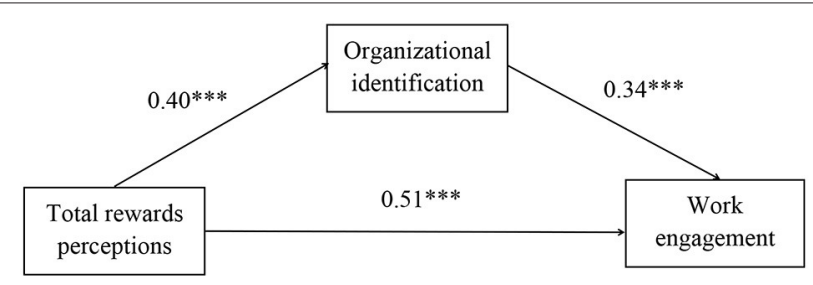

FIGURE 2 | The SEM analysis conducted to examine the pathways among total rewards perceptions, organizational identification, and work engagement. The control variables are not included in the presentation of the model. ${ }^{\star * \star} p<0.001$.

have explored the correlation between total rewards perceptions and work engagement, or organizational identification and work engagement, but have not presented the correlation among the three variables. This study found that WLBP, DCOP, WCP, and WLP correlated significantly and positively with work engagement. The obtained results corroborate the finding of a previous study (Gulyani and Sharma, 2018), which indicated that a high level of monetary rewards and non-monetary rewards may foster employee engagement in work. Employees who were offered a reward package that is consistent with their personal preferences were more likely to engage in work (Pregnolato et al., 2017). Bakker et al. (2014) indicated that work resources such as training, development opportunities, and additional benefits can motivate employees to involve themselves in work.

This study found that DCOP of total rewards perceptions had a stronger positive relationship with work engagement than WLBP, WCP, and WLP. It was consistent with existing research (Scott and McMullen, 2010), which reported that quality of work career development, organizational culture, and work-life balance all have a greater impact on work engagement than pay. Hulkko-Nyman et al. (2012) estimated that non-monetary rewards have a greater correlation with work engagement than monetary rewards. Kindergarten is perceived as a low-wage unit in China. The level of financial investment in kindergartens in China is much lower than that in OECD countries (Liu and Huang, 2019). The low monetary rewards are considered normal among kindergarten teachers. Moreover, teaching is a helping profession, with a great component of idealist motivation (Xu and $\mathrm{Du}, 2014)$. Thus, the impact of monetary rewards on work engagement is not as strong as the impact of non-monetary rewards on work engagement among kindergarten teachers.
This study also found that kindergarten teachers' total rewards perceptions were positively related to organizational identification. The finding was also in agreement with a previous study (Yang and Yang, 2015). Past research has shown that employees develop a positive attitude toward the workplace when they have access to rewards such as benefits, career development opportunities (Abid et al., 2015), and pay rise (Oishi et al., 2011). Other studies have stated that total rewards have a significant positive impact on organizational support, which was closely related to organizational identification (Smit et al., 2015; Zagenczyk et al., 2020). In China's cultural context, people have a strong concept of collectivism. Collectivists are more likely to see themselves as part of the organization, show more attachment to the organization, take pride in their membership, and have good organizational identification in a collectivist climate (Hofstede, 2003; Roth et al., 2011). Therefore, the influence of kindergarten teachers' total rewards perceptions on organizational identification should also be considered in the cultural context of Chinese collectivism.

We also found that the influence of WCP and WLP is greater than that of WLBP and DCOP. This result contradicts the finding from previous research in the Western context (Goulet and Frank, 2002; Steijn and Leisink, 2006), which stated that monetary rewards have limited impact on employees' organizational commitment. However, the result is consistent with research on Chinese organizations (Chiu et al., 2002; Miao et al., 2013), which found that monetary rewards (e.g., pay, fringe benefits) are the main factors that affect organizational commitment.

This study suggested that organizational identification was positively correlated with teachers' work engagement. The finding was in accordance with previous studies (Zhang et al., 2018, 2020; Li et al., 2020), which indicated that the greater organizational identification, the higher level of employee engagement in the work. Organizational identification enables employees to internalize the success of the organization into their success; thus, it has a positive impact on work engagement (Karanika-Murray et al., 2015).

Rewards from the Kindergarten can motivate teachers to focus and engage at work, while teachers' attitudes toward work engagement vary from context to context. Kindergarten teachers have different needs and expectations in terms of rewards. For instance, some employees expect material rewards in return for their hard work, while others expect return in the form of nonmonetary rewards (Nazir et al., 2016). Therefore, examining the total rewards will help identify the combinations of rewards that motivate Kindergarten teachers to engage in work.

The present study found that organizational identification partially mediated the relationship between total rewards perceptions and work engagement among kindergarten teachers, which fit the Social Exchange Theory. This theory takes the exchange between organization and employees as the core (Blau, 1964). Organizations provide employees with material and emotional support, employees identify with the organization, and the exchange relationship arises (Blau, 1964; Emerson, 1976). The quality and sustainability of the exchange are affected by the rewards obtained by both parties through the exchange (Homans, 
1958). When employees are rewarded for their hard work, they participate in an exchange that increases their work engagement for organization (Gujral and Jain, 2013). Some empirical studies indicated that offering rewards from organization to employees implies that the organization expects to engage in a social exchange with them, and an influential psychological contract is established between organization and employees (Williamson et al., 2009; Newman and Sheikh, 2012b). Meanwhile, Social Identity Theory states that the strong relationship between employees and the organization may motivate employees to give their best for the organization (Brown, 2017; Pan et al., 2019) and increase their level of engagement (Wang and Tseng, 2019). When kindergarten teachers get the expected economic or non-economic rewards from the organization, in return, they will have a stronger sense of identity with kindergarten, form a positive psychological state, and immerse themselves in their work (Blau, 1986; Gulyani and Sharma, 2018). The Conservation of Resources Theory proposes that individuals with more resources not only will try their best to maintain and protect their existing resources but also are more capable of acquiring new resources (Hobfoll, 1989, 2011), thus exhibiting more positive mental states and behaviors (Halbesleben and Wheeler, 2008). Gorgievski and Hobfoll (2008) also indicated that people with ample resources are more likely to approach their work with energy and enthusiasm; thus, they have higher levels of engagement in work. The total rewards system, as an effective job resources program, may achieve the goal of creating positive feelings among teachers (Bakker et al., 2014) and affect employee organizational identification (Hwang and Jang, 2020). Individuals with high levels of organizational identification are more likely to enhance their work engagement (Riketta, 2005). Therefore, kindergarten teachers' total rewards perceptions not only influence work engagement directly but also indirectly affect work engagement by increasing their organizational identification.

\section{Limitations and Future Research Directions}

The present study has several limitations that need to be emphasized. First, the data for this study were collected from three provinces in China, which lack diverse national settings. Future studies could expand the scope of data collection as far as possible. Second, a cross-sectional research design was used in this study; thus, it cannot predict to what extent changes in kindergarten teachers' total rewards perceptions and organizational identification will lead to changes in work

\section{REFERENCES}

Abid, G., Zahra, I., and Ahmed, A. (2015). Mediated Mechanism of Thriving at Work between perceived organization support, innovative work behavior and turnover intention. Pakistan J. Commer. Soc. Sci. 9, 982-998.

Armstrong, M., and Stephens, T. (2005). A Handbook of Employee Reward Management and Practice. London: Kogan Page Business Books.

Ashforth, B. E., Harrison, S. H., and Corley, K. G. (2008). Identification in organizations: an examination of four fundamental questions. J. Manage. 34, 325-374. doi: 10.1177/0149206308316059 engagement. A longitudinal approach should be used to validate the causal relationship between kindergarten teachers' total rewards perceptions, organizational identification, and work engagement in future studies. Third, we used the Social Exchange Theory and Conservation of Resources Theory to explain the relationship among study variables and mediating effect of organizational identification, which have certain limitations, and other theoretical perspectives should be further explored. Finally, the mediating effect of organizational identity was small, suggesting that other mediators could explain the relationship between teachers' total rewards perceptions and work engagement. More mediating variables should be examined among total rewards perceptions, organizational identification, and work engagement relationship.

\section{Conclusions}

This study contributes to enriching the existing research literature and finds that except for the direct relationship, the relationship between total rewards perceptions and work engagement was partially mediated by organizational identification among Chinese kindergarten teachers. We use Social Exchange Theory and Conservation of Resources Theory to explain the mediating role of organizational identification. Other possible mediators between total rewards perceptions and work engagement and other antecedent variables of work engagement deserve more in-depth research and exploration.

\section{DATA AVAILABILITY STATEMENT}

The raw data supporting the conclusions of this article will be made available by the authors, without undue reservation.

\section{ETHICS STATEMENT}

The studies involving human participants were reviewed and approved by The Ethics Committee of College of Education, Huaibei Normal University. The patients/participants provided their written informed consent to participate in this study.

\section{AUTHOR CONTRIBUTIONS}

DJ and LC designed the study, reviewed, and revised the article together. DJ wrote the original draft of the manuscript. LC collected and analyzed the survey data. All authors contributed to the article and approved the submitted version. 
Blau, P. M. (1986). Introduction to the Transaction Edition, Exchange and Power in Social Life, Transaction Books. New Brunswick, NJ: Routledge.

Brown, A. D. (2017). Identity work and organizational identification. Int. J. Manag. Rev. 19, 296-317. doi: 10.1111/ijmr.12152

Chiboiwa, M. W., Samuel, M. O., and Chipunza, C. (2010). An examination of employee retention strategy in a private organisation in Zimbabwe. Afr. J. Bus. Manag. 4, 2103-2109. doi: 10.1016/j.tre.2009.12.001

Chinyio, E., Suresh, S., and Salisu, J. B. (2018). The impacts of monetary rewards on public sector employees in construction: a case of Jigawa state in Nigeria. $J$. Eng. Design Technol. 16, 125-142. doi: 10.1108/JEDT-12-2016-0098

Chiu, R. K., Wai-Mei Luk, V., and Li-Ping Tang, T. (2002). Retaining and motivating employees: compensation preferences in Hong Kong and China. Person. Rev. 31, 402-431. doi: 10.1108/00483480210430346

Coplan, R. J., Bullock, A., Archbell, K. A., and Bosacki, S. (2015). Preschool teachers' attitudes, beliefs, and emotional reactions to young children's peer group behaviors. Early Child. Res. Q. 30, 117-127. doi: 10.1016/j.ecresq.2014.09.005

Cropanzano, R., Rupp, D. E., and Byrne, Z. S. (2003). The relationship of emotional exhaustion to work attitudes, job performance, and organizational citizenship behaviors. J. Appl. Psychol. 88, 160-169. doi: 10.1037/0021-9010.88.1.160

Demerouti, E., and Bakker, A. B. (2011). The job demandsresources model: challenges for future research. SA J. Ind. Psychol. 37:974. doi: 10.4102/sajip.v37i2.974

Du L. J. (2013). Study of the impact of economic contract and psychological contract on organizational identification (Master's thesis), Zhejiang University of Finance and Economics, Hangzhou, 5, 42-46.

Duckworth, A. L., Quinn, P. D., and Seligman, M. E. P. (2009). Positive predictors of teacher effectiveness. J. Pos. Psychol. 4, 540-547. doi: $10.1080 / 17439760903157232$

Edwards, M. R., and Peccei, R. (2015). Perceived organizational support, organizational identification, and employee outcomes. J. Person. Psychol. 9, 17-26. doi: 10.1027/1866-5888/a000007

Emerson, R. M. (1976). Social exchange theory. Annu. Rev. Sociol. 2, 335-362. doi: 10.1146/annurev.so.02.080176.002003

Gorgievski, M., and Hobfoll, S. (2008). Work can burn us out or fire us up: conservation of resources in burnout and engagement. Handb. Stress Burnout Health Care. 1, 7-22.

Goulet, L. R., and Frank, M. L. (2002). Organizational commitment across three sectors: public, non-profit, and for-profit. Public Pers. Manage. 31, 201-210. doi: $10.1177 / 009102600203100206$

Guglielmi, D., Mazzetti, G., Villano, P., and Cantisano, G. T. (2017). The impact of perceived effort-reward imbalance on workplace bullying: also a matter of organizational identification. Psychol. Health Med. 23, 511-516. doi: 10.1080/13548506.2017.1363396

Gujral, H. K., and Jain, I. (2013). Determinants and outcomes of employee engagement: a comparatve study in informaton technology (IT) sector. Inte. J. Adv. Res. Manag. Soc. Sci. 2, 207-220. doi: 10.1002/eji.201570114

Gulyani, G., and Sharma, T. (2018). Total rewards components and work happiness in new ventures: the mediating role of work engagement. Evid. Based HRM 6, 255-271. doi: 10.1108/EBHRM-12-2017-0063

Guo, Y., and Zhang, L. (2016). The influence mechanisms of organizational socialization on work engagement - from the perspective of identity theory. Soft Sci. 30, 69-73.

Halbesleben, J. R. B., and Wheeler, A. R. (2008). The relative roles of engagement and embeddedness in predicting job performance and intention to leave. Work Stress 22, 242-256. doi: 10.1080/02678370802383962

Haslam, S. A., and Ellemers, N. (2006). Social identity in industrial and organizational psychology: concepts, controversies and contributions. Int. Rev. Ind. Org. Psychol. 20, 39-118. doi: 10.1002/0470029307.ch2

Hayes, A. F. (2009). Beyond Baron and Kenny: statistical mediation analysis in the New Millennium. Commun. Monogr. 76, 408-420. doi: $10.1080 / 03637750903310360$

Heneman, R. L., and Tansky, J. W. (2002). Human resource management models for entrepreneurial opportunity: Existing knowledge and new directions. Adv. Entrepr. Firm Emerg. Growth. 5, 55-81. doi: 10.1016/S1074-7540(02) 05004-3

Hobfoll, S. E. (1989). Conservation of resources: a new attempt at conceptualizing stress. Am. Psychol. 44, 513-524. doi: 10.1037/0003-066X.44.3.513
Hobfoll, S. E. (2011). Conservation of resource caravans and engaged settings. J. Occup. Organ. Psychol. 84, 116-122. doi: 10.1111/j.2044-8325.2010.02016.x

Hofstede, G. H. (2003). Culture's consequences: comparing values, behaviors, institutions and organizations across nations. Behav. Res. Ther. 41, 861-862. doi: 10.1016/S0005-7967(02)00184-5

Hogg, M. A., and Terry, D. J. (2000). Social identity and self-categorization processes in organizational contexts. Acad. Manag. Rev. 25, 121-140. doi: $10.5465 / \mathrm{amr} .2000 .2791606$

Homans, G. C. (1958). Social behavior as exchange. Am. J. Sociol. 63, 597-606. doi: $10.1086 / 222355$

Hu, L., Bentler, P. M. (1999). Cutoff criteria for fit indexes in covariance structure analysis: conventional criteria versus new alternatives. Struct. Equat. Model. 6, 1-55. doi: 10.1080/10705519909540118

Hulkko-Nyman, K., Sarti, D., Hakonen, A., and Sweins, C. (2012). Total rewards perceptions and work engagement in elder-care organizations. Int. Stud. Manag. Organ. 42, 24-49. doi: 10.2753/IMO0020-8825420102

Hwang, J., and Jang, W. (2020). The effects of job characteristics on perceived organizational identification and job satisfaction of the organizing committee for the olympic games employees. Manag. Sport Leis. 25, 290-306. doi: 10.1080/23750472.2020.1723435

Karanika-Murray, M., Duncan, N., Pontes, H. M., and Griffiths, M. D. (2015). Organizational identification, work engagement, and job satisfaction. J. Manag. Psychol. 30, 1019-1033. doi: 10.1108/JMP-11-2013-0359

Lam, L. W., Liu, Y., and Loi, R. (2016). Looking intra-organizationally for identity cues: Whether perceived organizational support shapes employees'organizational identification. Hum. Relat. 69, 345-367. doi: $10.1177 / 0018726715584689$

Li, H., Wang, Q., Nazir, S., Zhao, M., Asadullah, M. A., and Khadim, S. (2020). Organizational identification perceptions and millennials' creativity: testing the mediating role of work engagement and the moderating role of work values. Eur. J. Innov. Manag. doi: 10.1108/EJIM-04-2020-0165

Li, H. Y., and Wu, X. J. (2014). The relationship research of knowledge employee's commitment, capability and individual performance based on SET theory. Sci. Technol. Manag. Res. 34, 222-228.

Li, Y. P., and Wu, D. (2016). Procedural justice and employee's job engagement: the impacts of state anxiety and supervisor communication. Sci. Sci. Manag. S T 37, 138-149.

Liu, Q., and Huang, J. Q. (2019). A comparative study on the investment level of preschool education between China and OECD Countries. China Econ. Educ. Rev. 4, 72-86.

Mael, F., and Ashforth, B. E. (1992). Alumni and their alma mater: a partial test of the reformulated model of organizational identification. J. Organ. Behav. 13, 103-123. doi: 10.1002/job.4030130202

Miao, Q., Newman, A., Sun, Y., and Xu, L. (2013). What factors influence the organizational commitment of public sector employees in China? The role of extrinsic, intrinsic and social rewards. Int. J. Hum. Resour. Manag. 24, 3262-3280. doi: 10.1080/09585192.2013.770783

Morgan, J. C., Dill, J., and Kalleberg, A. L. (2013). The quality of healthcare jobs: can intrinsic rewards compensate for low extrinsic rewards? Work Empl. Soc. 27, 802-822. doi: 10.1177/0950017012474707

Muse, L., Harris, S. G., Giles, W. F., and Feild, H. S. (2008). Work-life benefits and positive organizational behavior: is there a connection? J. Organ. Behav. 29, 171-192. doi: 10.1002/job.506

Nazir, S., Shafi, A., Qun, W., Nazir, N., and Tran, Q. D. (2016). Influence of organizational rewards on organizational commitment and turnover intentions. Empl. Relat. 38, 596-619. doi: 10.1108/ER-12-2014-0150

Newman, A., and Sheikh, A. Z. (2012a). Organizational rewards and employee commitment: a Chinese study. J. Manag. Psychol. 27, 71-89. doi: 10.1108/02683941211193866

Newman, A., and Sheikh, A. Z. (2012b). Organizational commitment in Chinese small-and mediumsized enterprises: the role of extrinsic, intrinsic and social rewards. Int. J. Hum. Resour. Manag. 23, 349-367. doi: 10.1080/09585192.2011.561229

Oishi, S., Kesebir, S., and Diener, E. (2011). Income inequality and happiness. Psychol. Sci. 22, 1095-1100. doi: 10.1177/0956797611417262

Pan, N. D., Gruber, M., and Binder, J. (2019). Painting with all the colors: the value of social identity theory for understanding social entrepreneurship. Acad. Manag. Rev. 44, 213-215. doi: 10.5465/amr.2017.0504 
Perera, H. N., Vosicka, L., Granziera, H., and Mcilveen, P. (2018). Towards an integrative perspective on the structure of teacher work engagement. J. Vocat. Behav. 108, 28-41. doi: 10.1016/j.jvb.2018.05.006

Pregnolato, M., Bussin, M. H. R., and Schlechter, A. F. (2017). Total rewards that retain: a study of demographic preferences. SA J. Hum. Resour. Manag. 15:a804. doi: 10.4102/sajhrm.v15.804

Riketta, M. (2005). Organizational identification: a meta-analysis. J. Vocat. Behav. 66, 358-384. doi: 10.1016/j.jvb.2004.05.005

Roberts, D. R., and Davenport, T. O. (2002). Job engagement: why it's important and how to improve it. Empl. Relat. Today. 29, 21-29. doi: 10.1002/ert.10048

Roth, G., Assor, A., Kanat-Maymon, Y., and Kaplan, H. (2007). Autonomous motivation for teaching: how self-determined teaching may lead to self-determined learning. J. Educ. Psychol. 99, 761-774. doi: 10.1037/0022-0663.99.4.761

Roth, K., Kostova, T., and Dakhli, M. (2011). Exploring cultural misfit: causes and consequences. Int. Bus. Rev. 20, 15-26. doi: 10.1016/j.ibusrev.2010.06.005

Schaufeli, W. B., Salanova, M., González-rom,á, V., and Bakker, A. B. (2002). The measurement of engagement and burnout: a two sample confirmatory factor analytic approach. J. Happiness Stud. 3, 71-92. doi: 10.1023/A:10156309 30326

Scott, D., and McMullen, T. (2010). The Impact of Rewards Programs on Employee Engagement. Scottsdale, AZ: WorldatWork.

Shen, Y. (2007). Antecedents and consequences of organizational identification:a social exchange perspective. Acta Psychol. Sin. 5, 918-925. doi: 10.1360/aas-007-0297

Shen, Y., Todd, J., Cody, D., Yuan, D., Zhao, L., Dou, Y., et al. (2014). Linking perceived organizational support with employee work outcomes in a Chinese context: organizational identification as a mediator. Eur. Manag. J. 32, 406-412. doi: 10.1016/j.emj.2013.08.004

Smit, W., Stanz, K., and Bussin, M. (2015). Retention preferences and the relationship between total rewards, perceived organisational support and perceived supervisor support. SA J. Hum. Resour. Manag. 13:665. doi: 10.4102/sajhrm.v13i1.665

Soares, M. E., and Mosquera, P. (2019). Fostering work engagement: the role of the psychological contract. J. Bus. Res. 101, 469-476. doi: 10.1016/j.jbusres.2019.01.003

Song, J., Zhang, Y., Jia, C., and Ma, Y. (2019). The relationship between proactive personality and employee performance: the role of organizational socialization and organizational identification. Hum. Resour. Dev. China. 36, 19-31.

Stasio, S. D., Benevene, P., Pepe, A., Buonomo, I., Ragni, B., and Berenguer, C. (2020). The interplay of compassion, subjective happiness and proactive strategies on kindergarten teachers' work engagement and perceived working environment fit. Int. J. Environ. Res. Public Health. 17:4869. doi: $10.3390 /$ ijerph17134869

Steijn, B., and Leisink, P. (2006). Organizational commitment among Dutch public sector employees. Int. Rev. Admin. Sci. 72, 187-201. doi: 10.1177/0020852306064609

Strom, D. L., Sears, K. L., and Kelly, K. M. (2014). Work engagement: the roles of organizational justice and leadership style in predicting engagement among employees. J. Leadersh. Organ. Stud. 21, 71-82. doi: 10.1177/1548051813 485437

Stuart, A., and Whetten, D. A. (1985). Organizational Identity. Adm. Soc. 42, 166-190.

Van Dick, R., Christ, O., Stellmacher, J., Wagner, U., Ahlswede, O., Grubba, C., et al. (2004). Should i stay or should i go? Explaining turnover intentions with organizational identification and job satisfaction. Br. J. Manag. 15, 351-360. doi: 10.1111/j.1467-8551.2004.00424.x

Wang, C. J., and Tseng, K. (2019). Effects of selected positive resources on hospitality service quality: the mediating role of work engagement. Sustainability 11:2320. doi: 10.3390/su11082320

Wang, S. Y., Liu, H., and Lin, Y. M. (2016). The relationship between work boundary strength and employees' organizational identification: the moderating role of work boundary preference. Nankai Bus. Rev. 19, 81-90.

Wang, Z., Chen, L., and Li, X. (2015). Transformational leadership and work engagement: an affect perspective. Manage. Rev. 9, 120-129.

Williamson, I. O., Burnett, M. F., and Bartol, K. M. (2009). The interactive effect of collectivism and organizational rewards on affective organizational commitment. Cross Cult. Manag. Int. J. 16, 28-43. doi: $10.1108 / 13527600910930022$

WorldatWork. (2007). The Worldatwork Handbook of Compensation, Benefits \& Total Rewards. Hoboken, NJ: Wiley, 355-398.

$\mathrm{Xu}, \mathrm{L}$, and Du, S. Z. (2014). On the teacher's pursuit of better life. Res. Educ. Dev. 33, 72-77.

Yang, J., and Yang, J. (2015). Research on total rewards perception conceptualization and the impact on the organization and the identification: explanation from the motivation-hygiene theory. Econ. Manag. 37, 63-73.

Zagenczyk, T. J., Purvis, R. L., Cruz, K. S., Thoroughgood, C. N., and Sawyer, K. B. (2020). Context and social exchange: perceived ethical climate strengthens the relationships between perceived organizational support and organizational identification and commitment. Int. J. Hum. Resour. Manag. 1-20. doi: 10.1080/09585192.2019.1706618

Zhang, S., Ke, X., Frank, W. X. H., and Liu, J. (2018). Empowering leadership and employee creativity: a dual-mechanism perspective. J. Occup. Organ. Psychol. 91, 896-917. doi: 10.1111/joop.12219

Zhang, Y., Sun, J. J., Lin, C. V., and Ren, H. (2020). Linking core self-evaluation to creativity: the roles of knowledge sharing and work meaningfulness. J. Bus. Psychol. 35, 257-270. doi: 10.1007/s10869-018-9609-y

Conflict of Interest: The authors declare that the research was conducted in the absence of any commercial or financial relationships that could be construed as a potential conflict of interest.

Copyright (C) $2021 \mathrm{Ji}$ and Cui. This is an open-access article distributed under the terms of the Creative Commons Attribution License (CC BY). The use, distribution or reproduction in other forums is permitted, provided the original author(s) and the copyright owner(s) are credited and that the original publication in this journal is cited, in accordance with accepted academic practice. No use, distribution or reproduction is permitted which does not comply with these terms. 